PPPL- -2899

DE93 011983

\title{
GENERATION OF HIGH INTENSITY RF PULSES IN THE IONOSPHERE BY MEANS OF IN SITU COMPRESSION
}

\author{
S. C. Cowley, F. W. Perkins, and E. J. Valeo \\ Plasma Physics Laboratory, Princeton University \\ Princeton, New Jersey 08543
}

\begin{abstract}
We demonstrate, using a simple model, that high intensity pulses can be generated from a frequency-chirped modifier of much lower intensity by making use of the dispersive properties of the ionosphere. We show that a frequency-chirped pulse can be constructed so that its various components overtake each other at a prescribed height, resulting in large (up to one hundred times) transient intensity enhancements as compared to those achievable from a steady modifier operating at the same power. We examine briefly one possible application: the enhancement of plasma wave amplitudes which occurs as a result of the interaction of such a compressed pulse with pre-generated turbulence.
\end{abstract}




\title{
GENERATION OF HIGH INTENSITY RF PULSES IN THE IONOSPHERE BY MEANS OF IN SITU COMPRESSION
}

\author{
S. C. Cowley, F. W. Perkins, and E. J. Valeo \\ Plasma Physics Laboratory, Princeton University \\ Princeton, New Jersey 08543
}

Abstract We demonstrate, using a simple model, that high intensity pulses can be generated from a frequency-chirped modifier of much lower intensity by making use of the dispersive properties of the ionosphere. We show that a frequency-chirped pulse can be constructed so that its various components overtake each other at a prescribed height, resulting in large (up to one hundred times) transient intensity enhancements as compared to those achievable from a steady modifier operating at the same power. We examine briefly one possible application: the enhancement of plasma wave amplitudes which occurs as a result of the interaction of such a compressed pulse with pre-generated turbulence.

\section{Introduction}

The modification of ionospheric properties by means of irradiation by radio-frequency waves is a subject of continuing interest, see, for example [Radio Science, 1990]. When the frequency of the heater radiation is high enough so that the reflection point lies in the F-region, it is well-established that, at sufficiently high intensity, generation of short-wavelength plasma turbulence occurs in the vicinity of the turning point [Cheung, et. al., 1992]. The growth rate of the nonlinear, parametric processes leading to transfer of energy from the electromagnetic heater (pump) field to the electrostatic plasma (decay) waves have thresholds and growth rates dependent on the pump intensity. This intensity is substantially enhanced relative to that obtained for propagation in vacuum because of the "Airy swelling" in field strength due to the reduction of the vertical component of the group velocity

$$
\mathbf{v}_{g r} \equiv \frac{\partial \omega}{\partial \mathbf{k}}=\hat{\mathbf{k}} c\left(1-\frac{\omega_{p e}{ }^{2}}{\omega^{2}}\right)^{1 / 2}
$$

as the plasma density increases. The maximum amplitude enhancement $A$, which occurs within the last half-wavelength of the reflection point, is

$$
A=\xi^{1 / 6},
$$

where $\xi \equiv\left(l_{n} \omega / c\right)$ measures the total phase variation from the launch point to the reflection point. Here we have defined the gradient scale length of the electron density by $l_{n} \equiv n_{c r} /(d n / d x)$, where $n_{c r} \equiv \omega^{2} m /\left(4 \pi e^{2}\right)$, is the critical density at which the modifier frequency $\omega$ equals the local plasma frequency $\omega_{p e} . \xi$ is very large, typically of order $10^{4}$. 
A characteristic measure of strength, $S$, of the pump signal is the oscillatory energy of the electrons in the field, relative to their thermal energy, $T=m v_{t e}^{2}$. For a field with time variation $E(t)=E_{0} \cos (\omega t)$, the oscillatory velocity $v(t)=v_{o s} \sin (\omega t)$, with $v_{o s}=e E_{0} / m \omega$, and the ratio can be written $S \equiv\left(m v_{o s}^{2} / T\right)=\left(e E_{0} / m \omega v_{t e}\right)^{2}$. A typical value of $S$ at Arecibo is 0.003 [Wong and Brandt, 1990].

It would obviously be interesting to study the plasma behavior for larger pump amplitudes. Construction of a continuous source of substantially higher power would be costly. One way to realize some of the physical effects which would occur for a high intensity pump is to use the dispersive properties of the ionosphere $\left(\partial \mathbf{v}_{g r} / \partial \omega \neq 0\right)$ to temporally compress a pulse during its propagation. Since a pulse's total energy is conserved, the intensity enhancement factor is just the ratio of the width of the launched pulse to that of the compressed pulse. Because the group velocity dispersion is finite, the maximum width of the launched pulse is of order the time of propagation from the launcher to the compression point. The minimum width of the compressed pulse is a wave period. The maximum intensity enhancement is therefore a factor of $\xi^{2 / 3}(\lesssim 100)$ as compared to that emitted from a steady-state transmitter of the same peak power.

In order to see how this compression might be accomplished in plane-stratified ionosphere in which the electron density increases montonically with height, we refer to Figure 1. Suppose a transmitter launches a pulse with the intensity and frequency profiles shown in the lower two segments. The frequency has a single minimum at the pulse center (the time of maximum intensity) and increases toward the edges. If we decompose the pulse into a sequence of bundles, each of which carries an energy proportional to the launch intensity, then the propagation of each bundle is described by the ray equations of geometrical optics. The time dependence of the height of three such rays is shown at the top of the Figure. Consider first Ray \#2, launched with maximum intensity and minimum frequency. It propagates upward to its reflection height $h_{2}$, reaching there at time $t_{2}$ and then begins a downward trajectory. Ray \#1 is launched earlier, and at higher frequency. Since, from Eq. (1), $\partial v_{g r} / \partial \omega>0$, it's group velocity is larger than Ray \#2's. It reflects at a greater height $h_{1}$ and returns to $h_{2}$, coincidentally with Ray \#2's arrival. Similarly, Ray \#3, also launched with higher frequency than Ray \#2, "catches up" to ray \#2 at $h_{2}$ by virtue of its larger group velocity. With a suitable arrangement of phases the amplitudes of the three bundles add at $h_{2}$ at time $t_{2}$.

Below we demonstrate that this qualitative picture is recovered from the solution of the full wave equation describing the evolution of planar pulse propagation in a one-dimensional ionosphere. Within this model, the variation of transmitter power and frequency required to launch a pulse which converges at a prescribed height is obtained. The maximum field intensity at a convergence point in the F-region can be significantly (i.e. a hundred times) larger than that from a monochromatic transmitter of the same power. 


\section{Calculation of Pulse Compression}

To proceed quantitatively, we consider the scalar wave equation for the electromagnetic field amplitude in an unmagnetized, planar plasma with density variation in the $x$ direction

$$
\frac{\partial^{2} E}{\partial t^{2}}=c^{2} \frac{\partial^{2} E}{\partial x^{2}}-\omega_{p e}^{2}(x) E
$$

We set

$$
E=\text { Real } \exp (-i \omega t) E_{0}(x, t) .
$$

We assume, for concreteness, a linear density profile such that $x / l_{n}=\omega_{p e}^{2} / \omega^{2}-1$ and rescale the independent variables $\chi \equiv \omega x / c \xi^{-1 / 3}, \tau \equiv \omega t \xi^{-2 / 3}$. With these substitutions and the further assumption that the time variation of $E_{0}$ is slow relative to $\omega$, we obtain

$$
-2 i \frac{\partial E_{0}}{\partial \tau}=\frac{\partial^{2} E_{0}}{\partial \chi^{2}}-\chi E_{0}
$$

We can solve this equation by the method of generalized transforms, to obtain a Green's function or propagator. The solution in terms of the initial condition $E_{0}(\chi, 0)$ is

$$
E_{0}(\chi, \tau)=(i 2 \pi \tau)^{-1 / 2} \exp \left[-i\left(\frac{\tau^{3}}{24}+\frac{\tau \chi}{2}\right)\right] \int_{-\infty}^{\infty} d \chi^{\prime} E_{0}\left(\chi^{\prime}, 0\right) \exp \left[\frac{i}{2 \tau}\left(\frac{\tau^{2}}{4}+\chi-\chi^{\prime}\right)^{2}\right] .
$$

This is a general initial value solution to Eq. (5) written in terms of a propagator acting on the initial conditions. Let us take the pulse to be compressed at $\tau=0$ and then trace back in time to discover the required antenna emission. We take $E_{0}\left(\chi^{\prime}, 0\right)$ to be the gaussian $\exp \left[-\left(\chi^{\prime}-\bar{\chi}_{0}\right)^{2} / 4 \lambda\right]$. For such a gaussian pulse the integral can be performed analytically with the result

$$
E_{0}(\chi, \tau)=C\left(\lambda+i \frac{\tau}{2}\right)^{-1 / 2} \exp (-\Phi)
$$

where

$$
\Phi=\frac{1}{4} \frac{\left[\chi-\chi_{0}(\tau)\right]^{2}}{(\lambda+i \tau / 2)}+i\left(\frac{\tau^{3}}{24}+\frac{\tau \chi}{2}\right)
$$


with the ray trajectory $\chi_{0}(\tau)=\bar{\chi}_{0}-\tau^{2} / 4$. Here $C$ is a constant to be determined. The pulse envelope maintains its gaussian shape,

$$
\left|E_{0}\right|=C\left(\lambda^{2}+\frac{\tau^{2}}{4}\right)^{-1 / 4} \exp \left(-\Phi_{r}\right)
$$

with

$$
\Phi_{r}=\frac{\lambda}{4} \frac{\left[\chi-\chi_{0}(\tau)\right]^{2}}{\left(\lambda^{2}+\tau^{2} / 4\right)}=\frac{\hat{\lambda}}{4} \frac{\left[x+\left(t^{2} c^{2} / 4 l_{n}\right)\right]^{2}}{\left(\hat{\lambda}^{2}+\omega^{2} t^{2}\right)} \frac{\omega^{2}}{c^{2}}
$$

the real part of $\Phi$. Inspection of the pre-exponential factor in Eq. (7) reveals that the condition that $E_{0}$ be slowly varying compared to $\exp (-i \omega t)$ is that

$$
\hat{\lambda} \equiv \lambda \xi^{2 / 3}>>1
$$

Henceforth we choose $\bar{\chi}_{0}=0$ so that the pulse is a gaussian centered about $\chi=0$ at $\tau=0$. Within our model the plasma density is positive only for $x>-l_{n}$, which we therefore take as the launch point. We assume a maximum launch intensity $I_{P}$ at time $t_{l}=-2 l_{n} / c$. Under the assumption, Eq. (10), the pre-exponential in Eq. (7) can be considered constant during the launching of the pulse and the intensity is well represented as

$$
I(\tau)=I_{P} \exp \left(-2 \Phi_{r}\right)=C^{2} \frac{c}{8 \pi} \frac{1}{\xi^{1 / 3}} \exp \left(-2 \Phi_{r}\right)
$$

where, to the required accuracy,

$$
2 \Phi_{r}=\hat{\lambda}\left(\frac{r}{l_{n}}\right)^{2}\left(t-t_{l}\right)^{2} .
$$

The frequency at the antenna is $\omega_{l}(t)=\omega\left(1+\xi^{-2 / 3} \partial \Phi_{i} / \partial \tau\right)$, with $\Phi_{i}$ the imaginary part of $\Phi$. This can usefully be expressed as, dominantly,

$$
\omega_{l}(t)=\omega\left(1+\frac{1}{2} \frac{\Phi_{r}}{\hat{\lambda}}\right)
$$

The frequency variation is quadratic in time. More than $95 \%$ of the pulse energy is launched in the interval when $0 \leq \Phi_{r} \leq 1$, during which the relative frequency swing 


$$
\frac{\Delta \omega}{\omega}=\frac{\hat{\lambda}}{2}
$$

It is also of interest to compute the deviation in frequency $\Delta \omega$ at the point of maximum enhancement. We find

$$
\frac{\Delta \omega}{\omega_{0}} \equiv \frac{1}{\omega_{0}} \frac{\partial \tau}{\partial t}\left(\frac{d \Phi_{i}}{d \tau}\right)_{\chi=0}=\frac{\tau^{2}}{\xi^{2 / 3} 8\left(\lambda^{2}+\tau^{2} / 4\right)^{2}}\left[\lambda^{2}+\frac{3}{16} \lambda^{2} \tau^{2}+\frac{\tau^{4}}{64}\right] \sim \frac{c^{2} t^{2}}{32 l^{2}},
$$

so that frequency applied to the ionospheric plasma is always close to the plasma frequency, even in the presence of a considerable spread in transmitted frequency.

The maximum electric field (at $\tau=0, \chi=0$ ) is

$$
E_{P, M a x}=(8 \pi)^{1 / 2}\left(\frac{I_{P}}{c}\right)^{1 / 2} \xi^{1 / 6} \lambda^{-1 / 2}
$$

From Eq. (2), the corresponding result for a steady pump of intensity $I_{S}$,

$$
E_{S, M a x}=(8 \pi)^{1 / 2}\left(\frac{I_{S}}{c}\right)^{1 / 2} \xi^{1 / 6}
$$

At $\chi=0$, the duration of the amplitude enhancement is governed by the preexponential factor in Eq. (7). Thus, the amplitude enhancement $\sim \lambda^{-1 / 2}$ persists for an interval $\Delta \tau \sim 7 \lambda$, or $\Delta t \sim 7 \hat{\lambda} / \omega_{0} \sim 3.5 / \Delta \omega$, so that there is a tradeoff between the amplitude of a pulse and its duration. Table I gives representative enhancements and durations for nominal ionospheric parameters of $l_{n}=50 \mathrm{~km}$ and $\omega / 2 \pi=5$ $\mathrm{MHz}$, so that $\xi=5000$. The maximum amplitude enhancement is considerable. For $\hat{\lambda}=2$, the peak electric field energy density is 150 times that for a steady pump of the same intensity! (This limit is, strictly speaking, in violation of our assumption, Eq. (10). Typically, however, asymptotic results are reasonably accurate even when the "large parameter" is finite.) Moreover, the asymptotic decay in time of the intensity enhancement factor is $2 / \tau=2 \xi^{2 / 3} / \omega_{0} t$, so strong fields both rise and persist for many wave periods. We show in Figure 2 the maximum enhancement as a function of relative bandwidth for typical values of $\xi$. 
Table I. Intensity Enhancement and Duration ${ }^{a}$

\begin{tabular}{ccccc}
\hline$\hat{\lambda}$ & $\frac{\Delta \omega}{\omega}$ & $\begin{array}{c}\text { Intensity } \\
\text { Enhancement }\end{array}$ & $\begin{array}{c}\text { Enhancement } \\
\text { Duration }(\mu \mathrm{sec})\end{array}$ & $\begin{array}{c}\text { Launch } \\
\text { Duration }^{b}(\mu \mathrm{sec})\end{array}$ \\
\hline 2 & 0.25 & 150 & 0.4 & 940 \\
10 & 0.05 & 30 & 2.0 & 420 \\
50 & 0.01 & 6 & 10 & 188 \\
150 & 0.003 & 2 & 30 & 109 \\
\hline
\end{tabular}

${ }^{a} l=50 \mathrm{~km}, \nu=5 \mathrm{Mhz}$ assumed

${ }^{6}$ Defined by $\Phi_{r}=1$

We now consider qualitatively one possible effect of such short, intense pulses: the enhancement of the amplitude of pre-existing plasma wave turbulence. Such enhancement would likely lead to observable effects including the increased generation of suprathermal fluxes of electrons.

Consider the situation in which there exists a plasma wave with electric field variation $E_{\mathbf{k}} \cos (\mathbf{k} \cdot \mathbf{x}-\omega t)$, and an ion wave with density variation $\delta n_{\mathbf{i}} \cos (\mathbf{k} \cdot \mathbf{x})$, parametrically driven to nonlinear, steady amplitudes by a steady, monochromatic pump. If a pulse $\mathbf{E}_{P}(t) \cos (\omega t)$ is added to the driver, the plasma wave amplitude is changed an amount [Kruer, 1988]

$$
\Delta E_{\mathbf{k}}=\frac{2 \pi q^{2} \delta n_{i}}{m \omega} \int_{-\infty}^{\infty} d t \hat{\mathbf{k}} \cdot \mathbf{E}_{P}(x=0, t),
$$

where we have assumed the pulse duration short compared to the time for variation of $\delta n_{i}$.

Let $E_{L}$ denote the maximum electric field amplitude at the launch altitutde. Then

$$
\mathbf{E}_{P}(\chi=0, \tau)=\mathbf{e}_{P} E_{L} \frac{\xi^{1 / 6}}{(\lambda+i \tau / 2)^{1 / 2}} \exp [-\Phi(\chi=0, \tau)] .
$$

Here $\mathbf{e}_{P}$ is a unit vector in the direction of $\mathbf{E}_{P}$. The integral (18) is dominated by contributions where $\tau \gg \lambda$. In this limit $\Phi_{i}=i \tau^{3} / 96 \gg \Phi_{r}$ and the integral 
becomes

$$
\begin{aligned}
\int_{-\infty}^{\infty} d t \hat{\mathbf{k}} \cdot \mathbf{E}_{P}(x=0, t) & =\left(\hat{\mathbf{k}} \cdot \mathbf{e}_{P}\right) E_{L} \frac{2^{3 / 2} \xi^{5 / 6}}{\omega_{0}} \int_{0}^{\infty} \frac{d \tau}{\sqrt{\tau}} \cos \left(\frac{\pi}{4}+\frac{\tau^{3}}{96}\right) \\
& =\left(\hat{\mathbf{k}} \cdot \mathbf{e}_{P}\right) E_{L} \frac{2^{3 / 2} \xi^{5 / 6}}{\omega_{0}}(96)^{1 / 6} \Gamma\left(\frac{\pi}{6}\right) \\
& =5.6 \frac{E_{L} \xi^{5 / 6}}{\omega_{0}}\left(\hat{\mathbf{k}} \cdot \mathbf{e}_{P}\right) .
\end{aligned}
$$

The level of ion density fluctuations excited by the steady pump $E_{S}$ can be estimated from standard parametric instability [Perkins, et. al., 1974] or Zakharov theory [Dubois, et. al., 1990; Zakharov, 1989] to be

$$
\frac{\delta n_{i}}{n_{0}} \sim \frac{\left(\hat{\mathbf{k}} \cdot \mathbf{e}_{s}\right) E_{S}^{*} E_{\mathbf{k}}}{16 \pi n_{0} T} B,
$$

where $B$ is a response function of order unity. Combining (18) - (21) with $E_{S}=$ $\xi^{1 / 6} E_{L}$, one finds

$$
\begin{aligned}
\frac{\Delta E_{\mathbf{k}}}{E_{\mathbf{k}}} & =\frac{2.8\left|E_{L}\right|^{2} \xi}{16 \pi n_{0} T}\left\{\left(\hat{\mathbf{k}} \cdot \mathbf{e}_{0}\right)\left(\hat{\mathbf{k}} \cdot \mathbf{e}_{P}\right) B\right\} \\
& =\left(\frac{\partial P}{\partial A}\right) \frac{1.4 \xi}{n_{0} T c}\left\{\left(\hat{\mathbf{k}} \cdot \mathbf{e}_{0}\right)\left(\hat{\mathbf{k}} \cdot \mathbf{e}_{P}\right) B\right\}
\end{aligned}
$$

where $(\partial P / \partial A)=c\left|E_{L}\right|^{2} / 8 \pi$ is the incident power flux on the ionosphere. The effective radiated powier $P_{\text {eff }}$ needed to attain $\Delta E_{\mathbf{k}} / E_{\mathbf{k}} \sim 1$ is

$$
P_{e f f}=4 \pi R^{2}\left(\frac{n_{0} T c}{1.4 \xi}\right) \approx 120 \mathrm{MW}
$$

This power is comparable to existing ionospheric modification installations, so pulse compression should lead to interesting and observable modifications of ionospheric Langmuir wave turbulence.

\section{Conclusions}

In this letter we have shown how pulses of radio frequency radiation with intensities up to one hundred times greater than those attainable in steady-state can be obtained via frequency chirping. The intensity and frequency shape required at the antenna for a simple linear density profile are given in Eqs. (11) - (13). This technique may provide a cost-effective way of accessing a new high intensity regime for ionospheric modification. Estimates, based on parametric decay theory, indicate appreciable changes 
of ionospheric Langmuir turbulence will occur for chirped transmitter facilities with an effective radiated power exceeding $120 \mathrm{MW}$. A practical application of these ideas to a real ionosphere would need to consider additional effects including: relaxation of the 1-D assumption taking into account the frequency dependence of refraction, magnetic field effects, and understanding the sensitivity to incomplete knowledge of the density profile and the effect of small-scale density inhomogeneities.

Acknowledgments This work was supported by United States Department of Energy under Contract DE-AC02-76-CHO-3073 and The Office of Naval Research, Contract H00014-92-F-0112. 


\section{References}

P. Y. Cheung, et. al., Investigation of Strong Langmuir Turbulence in Ionospheric Modification, Journ. Geophys. Research 97, 10,575 (1992).

D. F. DuBois, H. A. Rose and D. Russell, Excitation of Strong Langmuir Turbulence in Plasmas Near Critical Density: Application to HF Heating of the Ionosphere, Journ. Geoph. Res. 95, 21,221 (1990).

F. W. Perkins, C. Oberman, and E. J. Valeo, Parametric Instabilities and Ionospheric Modification, J. Geophys. Res. 79, 1478 (1974).

W. L. Kruer, The Physics of Laser Plasma Interactions, Addison-Wesley, Redwood City, CA (1988), page 58.

Radio Science 25, Special Section: Ionospheric Modification in the Polar Region, pages 1249-1439 (1990).

A.Y. Wong and R. G. Brandt, Ionospheric modification - An outdoor laboratory for plasma and atmospheric science, Radio Science 25, 1251 (1990).

V. E. Zakharov, Collapse and Self-Focusing of Langmuir Waves, Chapter 5.3 in, Basic Plasma Physics, Selected Chapters, edited by A. A. Galeev and R. N. Sudan, North-Holland, New York (1989).

\section{gure Captions}

Figure 1. Qualtitative sketch illustrating the physics of pulse compression utilizing the dispersive properties of the ionosphere.

Figure 2. Intensity enhancement relative to that attainable from a steady modifier of the same peak power as a function of relative beandwidth $\Delta \omega / \omega$ for four values of $\xi \equiv l_{n} \omega / c$ typical of ionospheric experiments. 


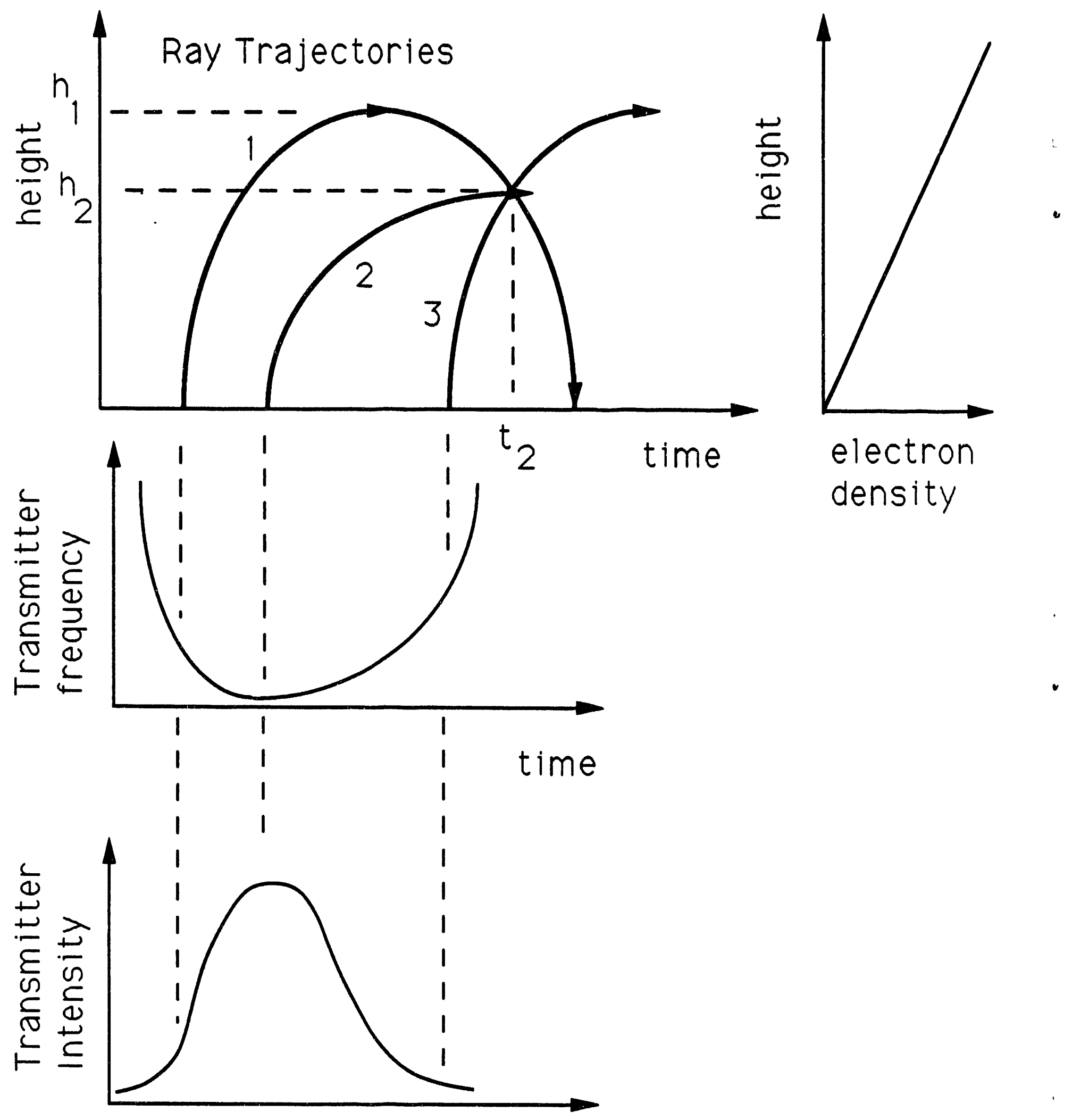

time 


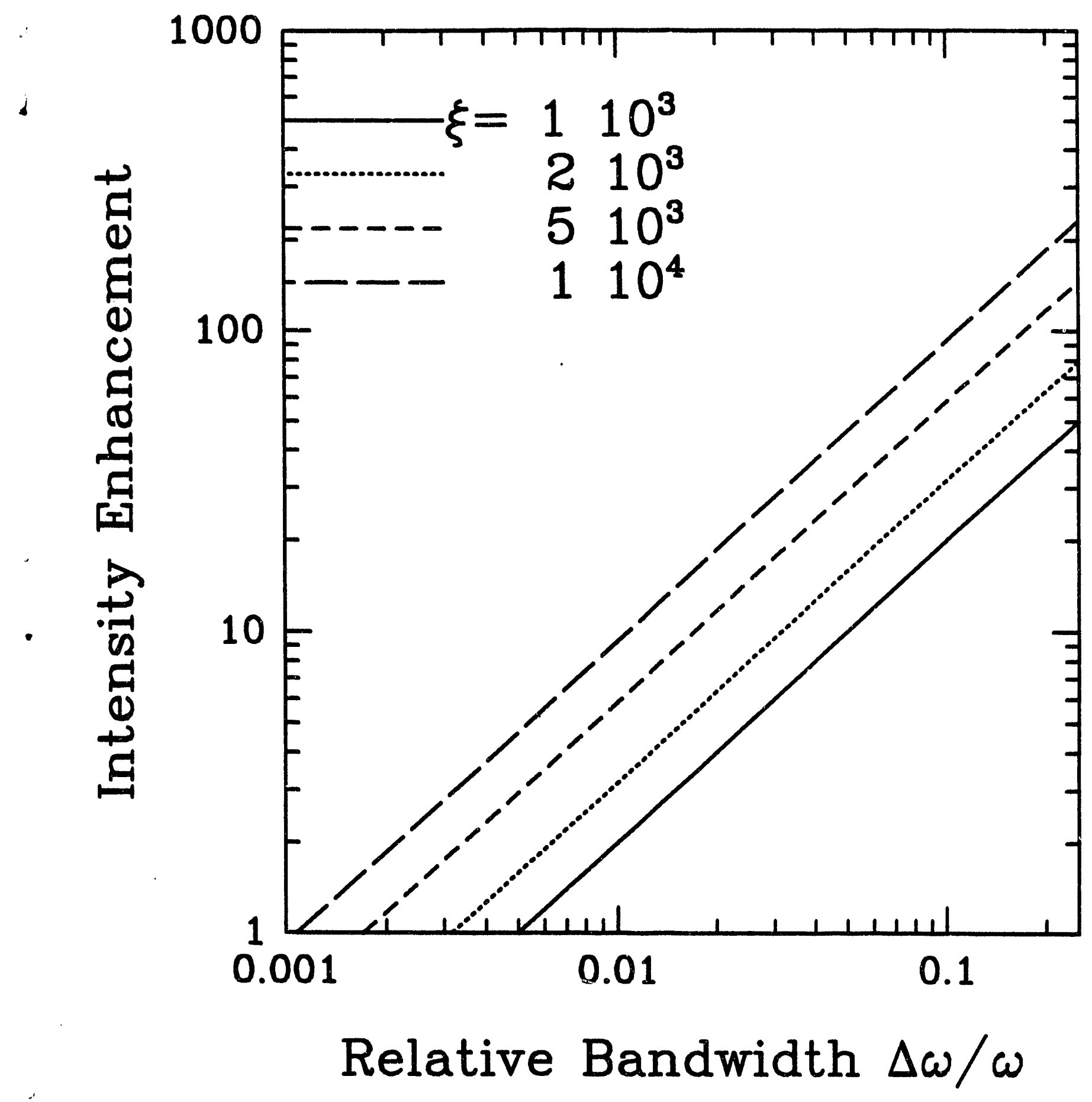

FIGURE 2 
Dr. F. Peotoni, Univ. of Wollongong, AUSTRALIA

Prof. M.H. Bremen, Univ. of Sydney, AUSTRALIA

Plaema Poscearch Lob., Austration Nat. Univ., AUSTRALIA

Prof. I.R. Jones, Finders Univ, AUSTralla

Prof. F. Cep, Inst for Theornticed Physics, AUSTAIA

Prot. M. Heindier, Instien ior Theoretische Phyeik, AUSTRIA

Prot. M. Cooseon, Aetronomiech InetiluUt, BELGIUM

Ecolo Poyclo Mrituiro, Leb. do Phy, Plaemas, EELCIUM

Commiscion-Europaen, DQ. XII-Fucion Prop., BELGIUM

Prof. A. Bouciaph, Prikeunivonitait Gent, BELCIUM

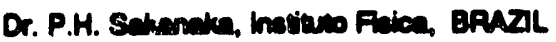

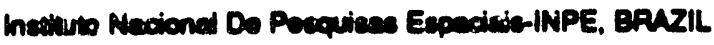

Dockerments Orice, Atomic Enovy of Caneda Ld., CAMADA

Dr. M.P. Bechynats, MPB Technolosies, Inc., CANADA

D. H.M. Skemoged, Univ. of Sackatchewen, CAMAOA

Prof. J. Toichmem, Univ. of Montried, CANADA

Prot. S.R. Sroenivasen, Univ. of Cedpay, CANADA

Prof. T.W. Johneten, INRS-Energie, CANADA

Dr. R. Bowon, Centre candien de theion magnsious, CANADA

Dr. C.R. James., Univ. Al Aberm, CAMADA

D. P. Luter Komonetetho Univerezita, CZECHOSLOVAKIA

Tho Librerien, Cuham Leroretory, ENCLAND

Libren, R31, Ruthertord Appleten Leboratony. ENGLAND

Mrs. S.A. Hulchineon, JET LBorey, ENGLAND

Dr. S.C. Sheme Univ. of South Pacific, FWI ISLANDS

P. Menonen, Univ. of Heleinid, FINLAND

Prot. M.N. Buesec, Ecobs Polyuchnique., FRANCE

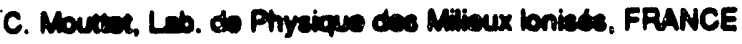

J. Pndat CENCAOAPACHE - EAt 506, FRANCE

Prot. E. Economow, Univ. of Crow, GREECE

M. C. Pinmi, Univ. of loomina, CPEECE

Dr. T. Mud, Acecterny Ensiogrphic Ser., HONG KONG

Preprint Librey. Hungerien Acaderny of Soi., HUNGAPY

Dr. B. Descuptin, Sara inst of Nuctacr Physics, INDIA

Dr. P. Kew, Inet for Plesma Racearch, INDLA

Dr. P. Rosenew, lered hat of Technology, ISAAEL

Libreien, Internationd Comer for Theo Phycice, ITALY

Mises C. Do Pab, Aseccinzions EUPATOMENEA, ITALY

Dr. G. Groses, letivte of Ficice del Piana, ITALY

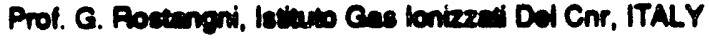

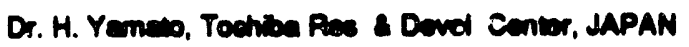

Prot. I. Kewakemi, Hirochime Univ., JAPAN

Prof. K. Nientemwe, Hiroshima Univ., dAPAN

Direcer, Jepen Alomic Enoroy Pasaarch Inst, LAPAN

Prof, S. Ioh, Kyuetu Univ., LAPAN

Pasearch Into. Cr., Nationd Instit for Fusion Science, JAPAN

Prot. S. Tencke, Kyoto Univ., JAPAN

Librery, Kyoto Univ., JAPAN

Prot. N. Inow, Univ. of Toloyo. LAPAN

Sacretery, Plama Section, Electonchnical Lab., JAPAN

S. Moni, Technical Adviecr, LAERM, MAPAN

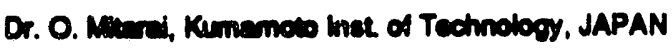

J. Hyoun-Sack, Korea Abomie Enwogy Poscerch Inet, KOAEA

D.I. Chai, Tho Korea Adv. Inet of Sa. \& Tech., KOAEA

Prot. 8.S. Liloy, Univ. of Weikab, NEW ZEALAND

Ines of Phyrics, Chinese Aced SCI PEOPLE'S REP. OF CHINA

Ubrey, Inst of Piasma Physics. PEOPLE'S REP. OF CHINA

Tanghua Univ. Lbrery. PEOPLE'S REPUBLC OF CHINA

2. U, S.W. Int Phycics, PEOPLE'S REPUBUC Of CHINA

Prof. J.A.C. Cabra, Inetivo Superior Tecnico, PORTUGAL

Dr. O. Pentus, ALI CUzA Univ., ROMANHA

Dr. J. o Vimiere, Fucion Sudies, AEC, S. AFPICA

Prot. M.A. Hemberg, Univ. of Natd, S. AFPiCA

Prot. D.E. Kon, Poheng lnat. of Sod. 4 Tech., SO. KOREA

Prot. C.I.E.MA.T, Fusion Divicion Libran, SPAN

Dr. L Siando, Univ. of UMEA, SWEDEN

Librery, Royed inct. of Tectnology, SWEDEN

Prot. H. Whrolineon, Chadmers Univ. of Tech., SWEDEN

Cente Ptyse. Dese Plasmas, Ecolo Pobrech, SWITZERLAND

Eibliostock, hat Voor Plasma-Fycica, THE NETHERLANDS

Acet Prot. Dr. 3. Calir, Middo Eeat Tech. Univ., TUAKEY

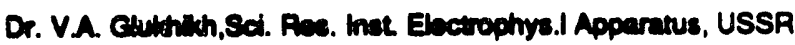

Dr. D.D. Ryutov, Steorian Branch of Acaderny of Soi., USSR

Dr. G.A. Eliecer, I.V. Kurchatev Inat, USSR

Lercien, The Ukr.SSA Acedermy of Sciences, USSR

Dr. LM. Kovizhnyth. Inst. of Conerd Phycica, USSA

Kemionctungaenteos GmbH, Zentrabibliothek, W. GERMANY

Bibliothek, Inst. For Plamabonchung, W. GERMANY

Prof. K. Schinder, Ruth-Univernity Bochum, W. GERMANY

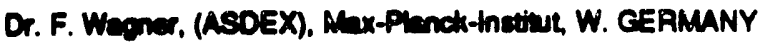

Libraien, Maxplenck-tnotite, W. CERMANY

Prot. R.K. Lanw, Inat of Plyjeios, ruecslavia 

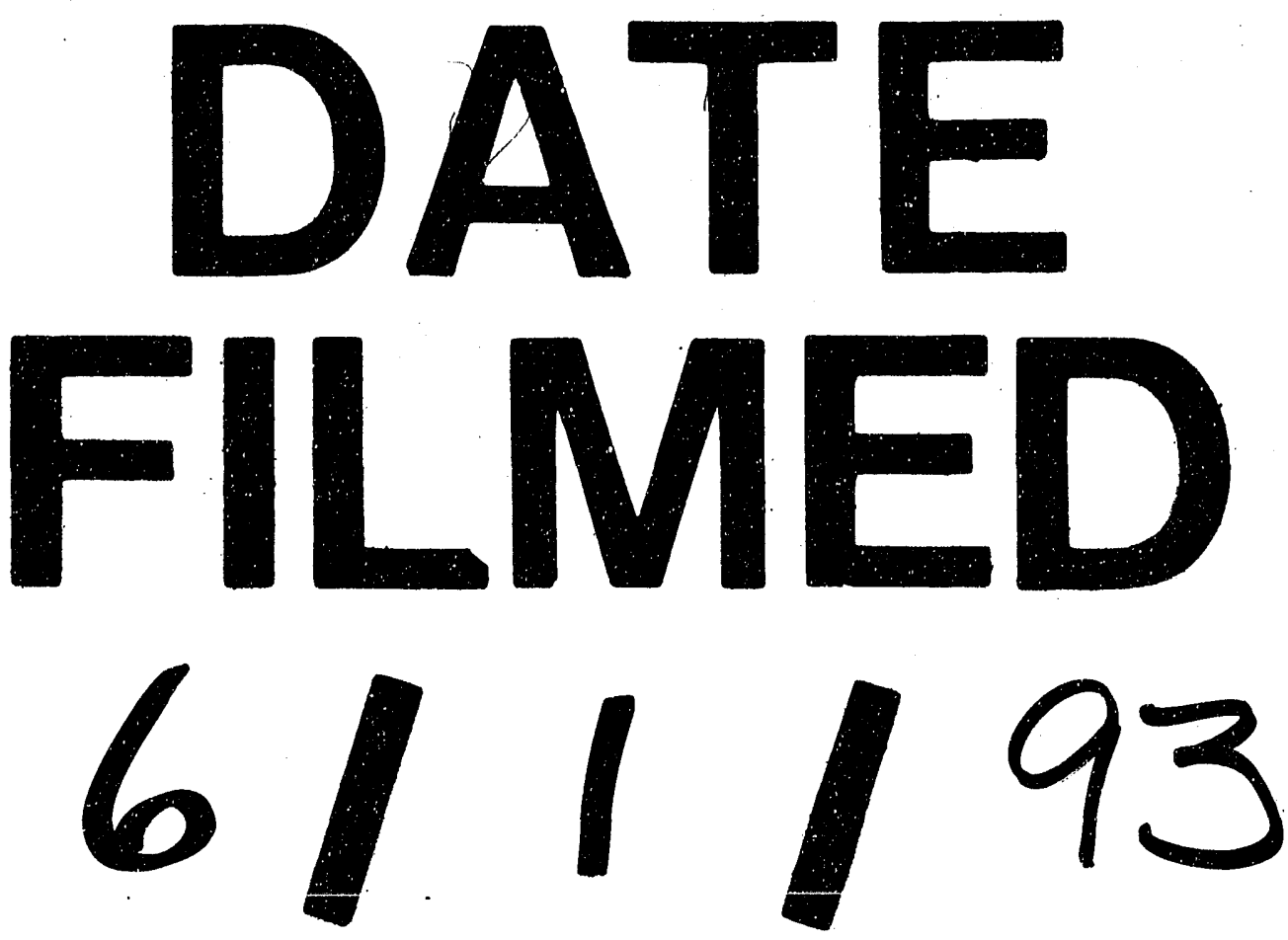
